\title{
Product liability, entry incentives and market structure
}

\author{
Stephen F. Hamilton ${ }^{\mathrm{a}}$, David L. Sunding ${ }^{\mathrm{b}}$ \\ ${ }^{a}$ Department of Agricultural and Resource Economics, University of Arizona, Economics Building 23, \\ Tucson, AZ 85721, USA \\ ${ }^{\mathrm{b}}$ Department of Agricultural and Resource Economics, University of California at Berkeley, \\ 207 Giannini Hall, Berkeley, CA 94720, USA
}

\begin{abstract}
The article characterizes the entry incentives provided by increases in product liability under various forms of competition. It is demonstrated that the entry of small, high-cost firms is likely to occur in imperfectly competitive markets when the average damage increases with industry output. Special cases are considered, including Cournot-Nash oligopoly and dominant firm-competitive fringe.
\end{abstract}

\section{Introduction}

The impact of product liability rules on market equilibrium is a central question in the economics of law. Indeed, a great deal of debate has focused on the observed structural changes in hazardous product industries that undergo an increased exposure to liability. At the center of this question is the empirical finding that the average scale of firms in hazardous product industries declined and de novo entry of small firms occurred in the 1967-1980 period of rapid changes in liability law. In one significant article, Ringleb \& Wiggins (1990) examined a wide range of hazardous industries and found that increases in potential liability are linked to substantial increases in the number of small firms operating in these sectors.

Our goal is to provide a simple, yet general, exposition of the market structure implications of increased producer exposure to liability. We characterize entry incentives in a variety of settings for the case where the extent of producer liability is determined by total industry 
output of a hazardous substance. This case encompasses some important real-life situations. One significant example is the case of liability for hazardous products such as cigarettes or pharmaceuticals (the synthetic estrogen diethylstilbestrol [DES] and the childhood diptheriapertussis-tetanus [DPT] vaccine being prime examples), where it is difficult, if not impossible, to allocate responsibility for individual injuries among companies. Another good example is the case of environmental health risk, where public health is affected by the total amount of some toxic substance. In such instances, the courts have increasingly turned toward the use of proportional liability rules. ${ }^{1}$

The assumption of proportional liability is also related to the burden of traditional regulation. Firms with larger facilities bear proportionally higher costs of complying with environmental and safety regulations than smaller firms. For example, firms with larger facilities face higher potential costs when large sites are more difficult to inspect or when more reports are required to meet regulatory requirements. Pashigian (1984) shows that increased regulation in the early 1970s led to a decrease in the optimal size of manufacturing plants, a finding that closely parallels the results of Ringleb \& Wiggins (1990) for increases in liability.

In this article, we characterize the marginal effects of an increase in product liability for several indicators of industry structure: output per firm (for various cost types), total industry output, small-firm entry, and incumbent market shares. ${ }^{2}$ We base our observations on a generalized conjectural variations model with asymmetric costs, endogenous entry, and complete capitalization. To capture a wide range of oligopoly outcomes, including the case of dominant firm(s) with a competitive fringe, the model allows conjectures to differ across firms. For various parameter values of the industry demand and external damage functions, we demonstrate that an increase in producer liability stimulates small-firm entry. In particular, small-firm entry is likely to occur when the average damage function increases in the level of industry output of the hazardous product. The intuition for such an effect is straightforward. If the average damage function associated with an environmental contaminant increases with industry output, a producer liability rule shifts the marginal benefit schedule of each incumbent firm downward but also makes it more inelastic. Increased producer liability may, thus, increase equilibrium price-cost margins and create an incentive for small-firm entry.

Our analysis indicates that the entry incentives provided by liability rules are richer and more pervasive than previous analyses suggest. Ringleb \& Wiggins (1990) and others hypothesize that the entry of small firms following increased liability exposure is the result of incomplete capitalization or latent risks that allow small firms to cease production before injury emerges. Such divestiture is liability reducing when the firms conducting the risky task have insufficient assets to pay damages and declare bankruptcy when suits are filed or, in the

\footnotetext{
${ }^{1}$ Market share liability was first applied in the DES case, Sindell v. Abbott Laboratories, and has since been imposed for health risks resulting from asbestos, the DPT vaccine, and, most recently, from cigarette consumption.

${ }^{2}$ Sunding \& Zilberman (1998) also consider the relationship between market structure and liability. Their analysis concerns the optimal apportionment of liability along the chain of production when a firm with some degree of market power produces a hazardous input.
} 
case of latent health risks, exit the industry before injury emerges. ${ }^{3}$ This idea that small-firm entry occurs through divestiture following increased producer liability is based on the common conception that structural considerations lead industry output to increase with entry (see, e.g., Seade, 1980a; Mankiw \& Whinston, 1986). Much of the force behind the divestiture claim rests on the fact that the observed entry in hazardous product industries is coupled with decreased industry output. If industry output decreases with entry in hazardous sectors, then intuition suggests that structural forces be ruled out as the precursor to entry.

This article shows that a decrease in industry output is, in fact, a necessary condition for small-firm entry to occur in response to increased producer exposure to liability. In general, entry can occur either following a parallel outward shift in marginal benefit, or, in the case of an oligopolistic industry, in response to a clockwise pivot in the marginal benefit schedule as firms respond to a relatively more inelastic marginal benefit function by increasing their price-cost margins. In the former case, increased product liability implies industry output declines (and exit occurs), whereas in the latter case industry output declines but entry occurs. Consequently, entry can only occur in response to increased liability exposure when industry output declines. The implication of this finding is that small-firm entry can be explained by more than divestiture incentives or incomplete capitalization alone.

The remainder of the article is organized as follows. Section 2 develops the basic liability model and discusses its relationship to other models of oligopoly and to other models commonly used in the liability literature. Section 3 derives the marginal impacts of an increase in producer liability on incumbent output levels and the number of small, high-cost firms. Section 4 highlights the importance of the shape of the damage function for the comparative statics results. Several special cases of the model are considered that emphasize the heretofore unrecognized point that entry incentives depend on the sign of the average damage relationship. Concluding comments are provided in Section 5.

\section{The model}

Consider an oligopoly model with endogenous entry, as previously studied by Besley (1989), Konishi (1990), Mankiw \& Whinston (1986), and Seade (1980a). The model distinguishes between small, high-cost firms and large, relatively cost-efficient firms on the basis of differences in marginal production costs (similar models of asymmetric-cost industries are studied by Dierickx, Matutes \& Neven, 1988, and Kimmel, 1992). Finally, the range

\footnotetext{
${ }^{3}$ Analyses based on incomplete capitalization include Boyd \& Ingberman (1994), van 't Veld (1997), and Watts (2000). These articles highlight the importance of treating industry structure as endogenous to the imposition of liability. Boyd \& Ingberman (1994) analyze the contractual relationships that emerge between upstream producers of a hazardous input and downstream contractors as a result of incomplete capitalization. They show that liability can lead to sorting whereby highly capitalized producers sell to highly capitalized contractors. van 't Veld (1997) argues that the familiar judgment-proof problem should be treated as endogenous to firms' financial decisions, as well as to competitive pressures in capital and output markets. Watts (1998) conducts a game-theoretic analysis of entry under different liability rules when solvency is important.
} 
of oligopoly outcomes is described through the use of conjectural variations parameters. ${ }^{4}$ Conjectures are allowed to differ in the model between low- and high-cost firms, which extends the conjectural variations approach to encompass other familiar forms of quantity competition such as the case of a dominant firm (or firms) with a competitive fringe.

We consider an equilibrium distribution of firm types. Denote the initial number of firms producing in equilibrium as $N=n_{l}+n_{h}$, where $n_{l}$ is the number of homogeneous low-cost firms, each with the cost function $c_{l}\left(y_{l}\right)$, and $n_{h}$ is the number of homogeneous high-cost firms, each with cost function $c_{h}\left(y_{h}\right)$. The output of a representative firm of each type is denoted $y_{l}$ and $y_{h}$, respectively, for the low- and high-cost firms. All firms maximize profit with respect to output, and attention is limited to unavoidable portions of liability exposure that result from a negative production externality in the industry.

To eliminate the usual incentives for divestiture, it is assumed that all firms in the industry are fully capitalized. Producer liability from hazardous production is modeled as a function of total industry output, and liability is apportioned on the basis of market share. This formulation is appropriate in the case of common pool health risks such as pesticide contamination of ground water, exposure to the DPT vaccine, ingestion of DES, cigarette smoking, and exposure to asbestos. The profit of each firm is

$$
\pi^{i}=[P(Y)-g(Y)] y_{i}-c_{i}\left(y_{i}\right), i=(l, h),
$$

where $Y=\Sigma_{i} y_{i}, P(Y)$ is the inverse demand function and $g(Y)$ is per-unit liability. Eq. (1) incorporates several common liability rules as special cases. In the case of proportional liability, for example, if total industry liability is $G(Y)$, an individual firms' share of liability payments is $G(Y) s_{i}=g(y) y_{i}$, where $s_{i}$ is the market share of firm $i$ and $g(Y)=G(Y) / Y$ is the average per-unit liability in the industry.

The following conditions are imposed to characterize the relative efficiency of a representative firm in each subgroup:

$$
\left.\frac{d c_{l}\left(y_{l}\right)}{d y_{l}}\right|_{y^{*}} \leq\left.\frac{d c_{h}\left(y_{h}\right)}{d y_{h}}\right|_{y_{h}{ }^{*}},
$$

and

$$
\left.\frac{d^{2} c_{l}\left(y_{l}\right)}{d\left(y_{l}\right)^{2}}\right|_{y_{l}^{*}} \leq\left.\frac{d^{2} c_{h}\left(y_{h}\right)}{d\left(y_{h}\right)^{2}}\right|_{y_{h^{*}} \cdot} .
$$

where the subscripts $l$ and $h$ denote the low- and high-cost firms, respectively. Condition (C1) states that the marginal cost of the representative low-cost producer is less than the marginal cost of the high-cost producer at their respective equilibria output levels. Condition (C2) states that a marginal expansion of output does not raise the marginal cost function of a low-cost firm by more than that of a high-cost firm. This condition eliminates from

\footnotetext{
${ }^{4}$ It is well understood that the conjectural variations framework has no valid dynamic foundation. However, it provides a convenient way to characterize the spectrum of oligopoly outcomes, and it is widely used in the literature.
} 
consideration the somewhat unusual case in which the representative high-cost firm has a higher marginal cost of production than the representative low-cost firm, as in equilibrium Condition (C1), yet has a greater capacity to expand production. That is, while we do not wish to excessively restrict the model by expressing the difference in efficiency in a global sense, it is important to maintain the identity of high- and low-cost firms by assuming that large, low-cost firms have greater scale economies than high-cost firms. ${ }^{5}$

Differentiating the profit expression of a representative firm in subgroup $i$ yields the first-order condition

$$
\pi_{y_{i}}^{i}=P-g+\delta_{i} y_{i}\left(P^{\prime}-g^{\prime}\right)-c_{y_{i}}^{i}=0
$$

and second-order condition

$$
\pi_{y_{i} y_{i}}^{i}=2 \delta_{i}\left(P^{\prime}-g^{\prime}\right)+\delta_{i}^{2} y_{i}\left(P^{\prime \prime}-g^{\prime \prime}\right)-c_{y_{i} y_{i}}^{i}<0,
$$

where $\delta=\partial Y / \partial y_{i}$ is the conjectural variations parameter. Conjectures are necessarily symmetric only within subgroups. The model thus encompasses several familiar cases. When conjectures are symmetric across all firms, the model reduces to cases of perfectly competitive behavior $\left(\delta_{i}=0, \alpha I\right)$, Cournot-Nash behavior $(\delta=1, \alpha i)$, and tacit collusion $(\delta=$ $\left.n_{i}, \alpha I\right)$. When conjectures differ across firms, the model reduces to the special case of low-cost dominant firm(s) with a high-cost competitive fringe with restrictions $\delta_{h}=0$ and $\delta_{i}=n_{l}$.

To address entry in the model, the number of firms is treated as a continuous variable following Besley (1989), Mankiw \& Whinston (1986), and Seade (1980a). We assume that changes in liability structure are modest enough to not affect the number of low-cost firms and, thereby, to confine attention to the entry (exit) of high-cost firms into (from) the industry. This modeling assumption is necessary to preserve the heterogeneous firm equilibrium described above in the face of entry, as low-cost firms in the model receive efficiency rents proportional to their cost advantages in the market. The efficiency rent, which accrues to some productive factor that is not explicitly modeled here (e.g., access to managerial talent, technology, or credit markets), limits the ability of a high-cost firm to shut down and reopen as a low-cost firm in the baseline equilibrium. In general, we can think of Condition (C1) as supporting an index of productive efficiency in the industry in which firms are ordered from lowest to highest marginal cost. If the index is a continuum, the efficiency rent is a continuous function of cost type that decreases to zero at the high-cost margin of entry. Thus, a change in liability exposure that affects industry profitability induces the entry (exit) of the least efficient firms into (from) the market until the industry equilibrium is reestablished at a new point on the continuum. For the case of two discrete subgroups of firms, as modeled here, entry (exit) into (from) the high-cost industry subgroup occurs until the zero

\footnotetext{
5 The reader should note that Condition (C2) is likely to be met in practical applications, as low-cost firms may have higher marginal costs at low levels of output yet be operating at a scale that is well beyond any crossing of marginal cost with that of high-cost firms. It is somewhat implausible to imagine small, high-cost firms investing in capacity sufficient to make them more efficient than large low-cost producers at high levels of output.
} 
profit condition is met for a representative high-cost firm. Thus, the number of high-cost firms in the industry, $n_{h}{ }^{*}$, is the solution to

$$
\pi^{h *}=\left[P\left(Y^{*}\right)-g\left(Y^{*}\right)\right] y_{h}^{*}-c_{h}\left(y_{h}^{*}\right)=0,
$$

where $Y^{*}=n_{l} y_{l}^{*}+n_{h}{ }^{*} y_{h}{ }^{*}$ in a symmetric subgroup equilibrium. The equilibrium value, $n_{h}{ }^{*}$, is determined simultaneously with $y_{l}{ }^{*}$ and $y_{h}{ }^{*}$ using the first-order Condition (2) and the entry Eq. (4). ${ }^{6}$

The following conditions are imposed for the existence and stability of the equilibrium. The conjectured residual marginal benefit is a decreasing function of firm output and declines faster than the marginal cost curve of either type of firm, or

$$
\delta_{i} B^{\prime}=\delta_{i}\left(P^{\prime}-g^{\prime}\right)<0,
$$

where $B^{\prime}=\left(P^{\prime}-g^{\prime}\right)$ is the slope of the marginal benefit schedule, and

$$
k_{i}>0 \text {, }
$$

where $k_{i}=c_{y_{i} y_{i}}^{i}$. The following restriction is also imposed:

$$
\omega_{i}=B^{\prime}+\delta_{i} y_{i} B^{\prime \prime}<0 .
$$

Conditions (C3), (C4), and (C5) ensure the existence of equilibrium and imply that outputs are strategic substitutes (see Seade, 1980b; Novshek, 1985; and Dixit, 1986). These conditions are imposed purely for mathematical convenience: when second-order Condition (3) holds, the conditions are equivalent to the coefficient matrix in Eq. (5) below having a negative trace and a positive determinant.

\section{The structural implications of a change in producer liability}

The effect of modifying the product liability rule can be expressed as a shift in the liability function. Following Dixit (1986) and Williamson (1991), let $\theta$ represent a shift parameter in the liability function; that is, $g=g(Y ; \theta)$. From an initial zero-liability position, the parameter $\theta$ represents a movement to a producer liability rule for the control of an environmental health risk. ${ }^{7}$

The effect of a change in product liability is computed by totally differentiating first-order Condition (2) for both low- and high-cost types and entry Condition (4), making use of the envelope theorem. Combining equations, the system is

$$
\left[\begin{array}{ccc}
\lambda_{l} & n_{h} \omega_{l} & y_{h} \omega_{l} \\
n_{l} \omega_{h} & \lambda_{h} & y_{h} \omega_{h} \\
n_{l} B^{\prime} y_{h} & \left(n_{h}-\delta_{h}\right) B^{\prime} y_{h} & B^{\prime} y_{h}^{2}
\end{array}\right]\left[\begin{array}{l}
d y_{l} \\
d y_{h} \\
d n_{h}
\end{array}\right]=\left[\begin{array}{c}
g_{\theta}+\delta_{l} y_{l} g_{\theta^{\prime}} \\
g_{\theta}+\delta_{h} y_{h} g_{\theta^{\prime}} \\
g_{\theta} y_{h}
\end{array}\right] d \theta,
$$

\footnotetext{
${ }^{6}$ It is assumed that $n_{h}{ }^{*}$ is unique, as is the case when at least a portion of fixed costs is sunk (see Vickers, 1989).

7 The reader should note that the existence of a cause of action under centuries of tort law means that industries faced liability rules with positive probability even before the institutionalization of product liability.
} 
where $\lambda_{i}=\pi_{i y_{i}} y_{i}+\left(n_{i}-\delta_{i} \omega_{i}<0\right.$ by Condition (C5) and second-order condition Eq. (3). Denoting the coefficient matrix in Eq. (5) by $\Omega$, its determinant is

$$
\operatorname{Det}(\Omega)=-y_{h}^{2} B^{\prime} k_{l} \pi_{y_{h} y_{h}}^{h},
$$

which is negative by the second-order Condition (2) with the stability Condition (C4).

The effect of the change in liability on the output of the representative high- and low-cost firm is

$$
\frac{d y_{h}}{d \theta}=\frac{\delta_{h} y_{h} \Phi}{B^{\prime} \pi_{y_{h} y_{h}}^{h}},
$$

and

$$
\frac{d y_{l}}{d \theta}=\frac{\left[\delta_{l} y_{l} k_{h}-\delta_{h} B^{\prime}\left(\delta_{l} y_{l}-\delta_{h} y_{h}\right)\right] \Phi}{B^{\prime} k_{l} \pi_{y_{h} y_{h}}^{h}},
$$

respectively, where $\Phi=\left(g^{\prime}{ }_{\theta} B^{\prime}-g_{\theta} B^{\prime \prime}\right)$ is a transformation of the cross-elasticity of the marginal benefit schedule with respect to $Y$ and $\theta$. Specifically, the parameter $\Omega$ may be interpreted in elasticity form as $\Phi=g_{\theta} B^{\prime} / Y\left(\epsilon_{\theta},-\epsilon_{B^{\prime}}\right)$, where $\epsilon_{B^{\prime}}=B^{\prime \prime} Y / B^{\prime}$ is the elasticity of the slope of marginal benefit and $\epsilon=g^{\prime}{ }_{\theta} Y / g_{\theta}$ is the change in the unit liability elasticity, which, from an initial zero-liability position, is the elasticity of average damages. ${ }^{8}$ For an increase in liability $\left(g_{\theta}>0\right), \Phi$ is negative if the change in the unit liability elasticity is positive and exceeds the elasticity of the slope of marginal benefit. Manipulating the first-order Condition (2) for the representative high- and low-cost firm, Eq. (8) is expressed as

$$
\frac{d y_{l}}{d \theta}=\frac{\left[\delta_{l} y_{l} k_{h}+\delta_{h}\left(c_{y_{h}}^{h}-c_{y_{l}}^{l}\right)\right] \Phi}{B^{\prime} k_{l} \pi_{y_{h} y_{h}}^{h}} .
$$

Note that the signs of Eq. (7) and Eq. (9) conform to the sign of $\Omega$ by Conditions (C1), (C3), (C4), and the second-order condition of a high-cost firm in Eq. (3).

A change in liability exposure affects the number of high-cost firms as

$$
\frac{d n_{h}}{d \theta}=\frac{g_{\theta} k_{l} \pi_{y_{h} y_{h}}^{h}-\Phi\left[\delta_{l} n_{l} y_{l} k_{h}+\delta_{h} y_{h} k_{l}\left(n_{h}-\delta_{h}\right)+n_{l} \delta_{h}\left(c_{y_{h}}^{h}-c_{y_{l}}^{l}\right)\right.}{B^{\prime} y_{h} k_{l} \pi_{y_{h} y_{h}}^{h}},
$$

where the first-order conditions in Eq. (2) have been used as in Eq. (9). Conditions (C3) and (C4) imply that the expression in square brackets is positive. For the analysis to follow, it is helpful to express this term as $\Psi-\delta_{h}{ }^{2} y_{h} k_{l}$, where $\Psi=\delta_{l} y_{l} n_{l} k_{h}+\delta_{h} y_{h} n_{h} k_{l}+\delta_{h} n_{l}\left(c_{y_{h}}^{h}\right.$ $-c_{y_{l}}^{l}$ ). In response to a change in producer liability in the hazardous product industry, the degree of entry (exit) of high-cost firms into (from) Eq. (10) depends on the value of the

\footnotetext{
${ }^{8}$ The sign of the elasticity of the slope of marginal benefit has important implications in oligopoly models with entry, as discussed by Seade (1980a) and Besley (1989). Dierickx, Matutes \& Neven (1988) describe the influence of convexity on the comparative statics of an asymmetric-cost oligopoly.
} 
conjectural variations parameters, the level effect of the unit liability function, $\mathrm{g}_{\theta}$, and the rotation effect $g_{\theta}^{\prime} \cdot{ }^{9}$. For an increase in liability, the first term in Eq. (10) is negative as the level effect of the liability function reduces the equilibrium profit margin and places downward pressure on the number of high-cost firms in the industry. When the industry is perfectly competitive, this term captures the entire effect of producer liability, whereas, in noncompetitive environments, the degree of high-cost firm entry is also inversely related to $\Omega$. When the liability function is an increasing function of industry output, the marginal benefit schedule, $B$, becomes more inelastic after the imposition of liability, which reduces incumbent output in Eq. (7) and Eq. (9), increases price-cost margins in the industry, and allows a larger number of high-cost firms to produce in equilibrium.

PROPOSITION 1: The entry of high-cost firms occurs in response to increased producer liability when

$$
\epsilon_{\theta}>\frac{-Y\left[k_{l}\left(k_{h}-\delta_{h} B^{\prime}\right)-B^{\prime \prime} \Psi\right]}{B^{\prime}\left[\Psi-\delta_{h}^{2} y_{h} k_{l}\right]} .
$$

The proofs of all propositions are gathered together in the Appendix.

In Proposition 1, the entry of high-cost firms is more likely to occur when the marginal benefit schedule is convex and when the change in the unit liability elasticity is large. A large, positive change in the liability elasticity implies that the marginal benefit schedule becomes more price elastic at the equilibrium point, which, as we will see below, leads to greater shifting of liability into price. In cases where liability is shifted by more than $100 \%$ into price, entry can occur as the marginal profitability of production increases.

The effect of a change in producer liability on total industry output is calculated as $d Y / d \theta=y_{h}\left(d n_{h} / d \theta\right)+n_{h}\left(d y_{h} / d \theta\right)+n_{l}\left(d y_{l} / d \theta\right)$, which reduces to

$$
\frac{d Y}{d \theta}=\frac{g_{\theta} \pi_{y_{h} y_{h}}^{h}+\Phi \delta_{h}^{2} y_{h}}{B^{\prime} \pi_{y_{h} y_{h}}^{h}} .
$$

The denominator of Eq. (11) is positive by Condition (C3) and is the second-order condition of a high-cost firm in Eq. (3). An increase in producer exposure to liability reduces the total output of the hazardous product in Eq. (11) when the high-cost producer subgroup is competitive or, in the case of imperfectly competitive high-cost firms, when $\Phi \leq 0$. Conversely, an increase in producer liability increases total output if and only if

$$
g_{\theta}\left[2 \delta_{h} B^{\prime}-c_{y_{h} y_{h}}^{h}+\epsilon_{\theta} B^{\prime} \delta_{h}^{2} s_{h}\right]>0 .
$$

Thus, an increase in liability leads to greater industry output when the unit liability elasticity of has a large negative value. If the liability function is decreasing in industry output, such a perverse output effect may occur as the marginal benefit schedule shifts down but becomes more elastic following the liability rule. For example, if high-cost firms have constant

\footnotetext{
${ }^{9}$ The rotation effect is described by the pivot of the liability function through the initial equilibrium point.
} 
marginal cost, the condition in Eq. (12) is met when the change in the unit liability elasticity satisfies $\epsilon_{\theta}<-2 / \delta_{h} s_{h}$.

PROPOSITION 2: In response to increased producer liability, a contraction of total industry output is a necessary condition for high-cost entry to occur.

Unlike the case considered by Mankiw \& Whinston (1986) in which entry is assumed to always increase industry output, Proposition 2 implies that output always contracts with entry when producer exposure to liability increases in the hazardous sector. The intuition for this effect is as follows. The entry of firms following a change in market conditions occurs in two polar cases under oligopoly: in response to a parallel upward shift in marginal benefit or in response to a clockwise pivot of marginal benefit through the equilibrium point. ${ }^{10}$ In the first case, the size of the market (and industry output) increases, while, in the second case, entry occurs as the marginal benefit function becomes relatively less elastic and firms contract output to increase price-cost margins. When firms face increased exposure to product liability, the downward shift in marginal benefit creates a tendency for industry exit (and reduced industry output), so that entry can only occur in response to a sufficiently large clockwise pivot of the marginal benefit function. This pivot of the marginal benefit function to a more inelastic position leads firms to further contract output, thereby reinforcing the decline in industry production.

Proposition 2 highlights an important issue in the management of environmental health risks, as aggregate output in an imperfectly competitive industry may be greater than the socially optimal level while the equilibrium number of firms exceeds the optimal number. Thus, a potential outcome that cannot be ruled out is that a shift to a producer liability rule is associated with a net welfare loss.

The effect of a change in producer liability on the marginal benefit schedule is $d B / d \theta=B_{\theta}+B^{\prime}(d Y / d \theta)$, which, using Eq. (11), reduces to

$$
\frac{d B}{d \theta}=\frac{\delta_{h}^{2} y_{h} \Phi}{\pi_{y_{h} y_{h}}^{h}} .
$$

If the high-cost producer subgroup is imperfectly competitive, the marginal benefit of production increases if and only if $\Phi>0$. The change in the marginal benefit of production provides a convenient benchmark to describe the shifting of liability into price, as positive changes in marginal benefit imply a greater than $100 \%$ shift of unit liability into price. With competitive high-cost firms, liability is always shifted by exactly $100 \%$ into price. With noncompetitive high-cost firms, the degree of shifting of liability into price is determined by the value of $\Omega$. If the marginal benefit schedule is linear, for example, unit liability is shifted by more than $100 \%$ into price for all positive changes in the slope of the liability function.

We next examine changes in market share. The change in market share for a representative firm in subgroup $i$ is $d s_{i} / d \theta=Y^{-2}\left[Y\left(d y_{i} / d \theta\right)-y_{i}(d Y / d \theta)\right.$. Using Eq. (7), Eq. (9), and Eq.

${ }^{10}$ This point was originally made in Hamilton (1999). 
(11), a change in producer liability affects the market share of a representative high- and low-cost firm as

$$
\frac{d s_{h}}{d \theta}=\frac{-s_{h}\left[g_{\theta} \pi_{y_{h} y_{h}}^{h}-\Phi \delta_{h}\left(Y-\delta_{h} y_{h}\right)\right.}{B^{\prime} Y \pi_{y_{h} y_{h}}^{h}}
$$

and

$$
\frac{d s_{l}}{d \theta}=\frac{-g_{\theta} s_{l} k_{l} \pi_{y_{h} y_{h}}^{h}+\Phi\left[s_{l}\left(\delta_{l} Y k_{h}-\delta_{h}^{2} y_{h} k_{l}\right)+\delta_{h}\left(c_{y_{h}}^{h}-c_{y_{l}}^{l}\right)\right.}{B^{\prime} Y k_{l} \pi_{y_{h} y_{h}}^{h}},
$$

respectively. The first term in each expression represents an increase in market share, as an upward level effect in the liability function precipitates the exit of high-cost firms. The market share of a representative high-cost firm in Eq. (14) is positively related to $\Phi$, while the market share of a representative low-cost firm in Eq. (15) is positively related to $\Phi$ whenever $\left(\delta_{l} Y k_{h}-\delta_{h}^{2} y_{h} k_{l}\right)>0$. Adding and subtracting $\delta_{h} k_{l} Y$ to this term yields $\left(\delta_{l} Y k_{h}\right.$ $\left.-\delta_{h}^{2} y_{h} k_{l}\right)=Y\left(\delta_{l} c_{y_{h}}^{h} y_{h}-\delta_{h} c_{y_{l}}^{l} y_{l}\right)+\delta_{h} k_{l}\left(Y-\delta_{h} y_{h}\right)$, where the first term is positive by Eq. (C2) if the conjecture of a representative high-cost firm does not exceed that of a low-cost firm, and where the second term is positive in the allowable range of high-cost firm conjectures. Thus, in response to greater liability exposure, market share unambiguously increases when $\Phi \geq 0$ for either type of firm whenever the conjecture of a high-cost firm does not exceed that of a low-cost firm. For the remainder of our analysis on the effect of liability on incumbent market shares, we assume this condition is met. ${ }^{11}$

The following proposition provides conditions under which an increase in liability exposure increases the market share of incumbent firms in Eq. (14) and Eq. (15). This proposition then can be used with Proposition 1 to describe the various circumstances that lead to market share losses for low-cost incumbents, to market share gains for high-cost incumbents, and to the entry of high-cost firms. Inspecting Eq. (14) and Eq. (15), we have the following proposition.

\section{Proposition 3: An increase in producer liability}

1. increases the market share of high-cost firms when

$$
\epsilon_{\theta}<\frac{k_{h}-\delta_{h} B^{\prime}-\delta_{h} B^{\prime \prime} Y}{-B^{\prime} \delta_{h}\left(1-\delta_{h} s_{h}\right)}
$$

2. increases the market share of low-cost firms when

$$
\epsilon_{\theta}<\frac{y_{l} k_{l}\left(k_{h}-\delta_{h} B^{\prime}\right)-B^{\prime \prime} Y\left(\delta_{l} y_{l} k_{h}+\delta_{h}\left(c_{y_{h}}^{h}-c_{y_{l}}^{l}\right)\right.}{-B^{\prime}\left(y_{l}\left(\delta_{l} k_{h}-\delta_{h}^{2} s_{h} k_{l}\right)+\delta_{h}\left(c_{y_{h}}^{h}-c_{y_{l}}^{l}\right)\right)} .
$$

${ }^{11}$ It is hard to imagine a case in which high-cost firms conjecture a larger industry response to a change in output than low-cost firms. Small firms may perceive that they are more able to get away with undetected output increases than larger firms. 
Table 1

The implications of a change in product liability under competitive, dominant firm(s)/competitive fringe, and Nash-Cournot market structures

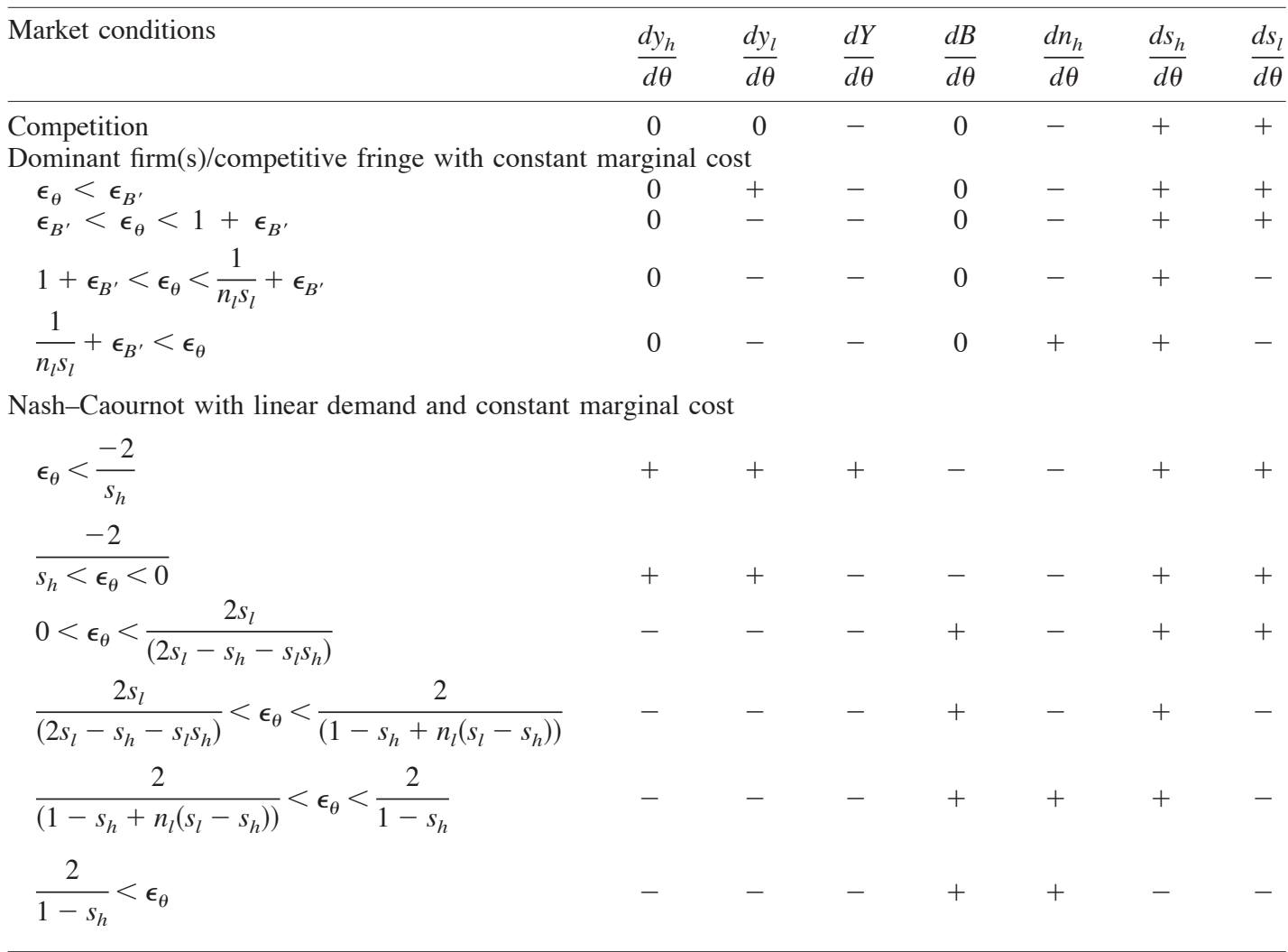

Proposition 3 provides general conditions under which increased producer liability increases incumbent market shares. As the following examples demonstrate, increased producer liability for environmental health risks can lead to a considerably rich variety of outcomes, including market share losses for low-cost incumbents, market share gains for high-cost incumbents, and high-cost entry. Table 1 summarizes the results of the above propositions for the various market structures considered in the examples below.

EXAMPLE 1: Consider a perfectly competitive equilibrium in the hazardous industry. In the competitive case, an increase in producer liability does not affect the production scale of either type of incumbent firm, and the additional liability cost precipitates the exit of high-cost firms. Consequently, total industry output decreases, and the market share of each incumbent firm increases. The magnitude of the industry output effect depends on the relative value of the unit liability function and the slope of marginal benefit at the equilibrium point. Thus, liability is shifted by exactly $100 \%$ into price. 
EXAMPLE 2: Consider the case of imperfectly competitive low-cost firms with a high-cost competitive fringe. Suppose low-cost firms have the cost function $c_{l}\left(y_{l}\right)=c_{l} y_{l}+F_{L}$, where $F_{L}$ denotes fixed costs. In this case, an increase in producer liability does not change the production scale of competitive high-cost incumbents but increases the production level of low-cost firms for sufficiently small changes in the unit liability elasticity. In particular, low-cost firms increase output in the face of greater liability exposure when the marginal benefit schedule becomes sufficiently more elastic following a change in legal structure.

With competitive high-cost firms, total output in the industry decreases and liability is shifted by exactly $100 \%$ into price following an increase in producer liability. Consequently, an increase in producer liability increases the market share of high-cost firms, regardless of the shape of the liability function. The market share of a representative low-cost firm can either increase or decrease following greater liability exposure, depending on the change in the unit liability elasticity.

Entry into the hazardous industry occurs following sufficiently large changes in the unit liability elasticity. The intuition for the entry effect can best be seen in the case of a linear marginal benefit schedule, $\mathrm{B}^{\prime \prime}=0$. In this case, $\epsilon_{\mathrm{B}^{\prime}}=0$ and high-cost, competitive firms enter the hazardous product industry following an increase in producer liability whenever the change in the unit liability elasticity satisfies $\epsilon_{\theta}>\left(n_{l} s_{l}\right)^{-1}$, or, alternatively, when the change in the residual liability elasticity for the low-cost subgroup, $\boldsymbol{\epsilon}_{\theta}^{l}=g_{\theta}^{\prime}\left(n_{l} y_{l}\right) / g_{\theta}$, exceeds unitary value. The key to understanding this entry condition is to note that firms in the high-cost fringe hold output constant; hence, entry (exit) occurs whenever the change in industry output unhinges from the change in the combined output of low-cost firms. With a competitive fringe, industry output declines linearly along the marginal benefit function in proportion to the increase in unit liability. When low-cost firms have constant marginal costs, the combined output reduction of low-cost firms exceeds this decline in industry output whenever $\epsilon_{\theta}^{l}>1$. The shortfall in low-cost firm production thereby accommodates entry.

With an isoelastic marginal benefit schedule, entry occurs in a wider range of circumstances. For example, if $B(Y)=A Y^{-\eta}$, where $\eta$ is the absolute value of the marginal benefit elasticity, $\epsilon_{B^{\prime}}=-(1+\eta)$ and high-cost competitive firm entry occurs following an increase in producer liability whenever $1+\eta+\epsilon_{\theta}>\left(n_{l} s_{l}\right)^{-1}$.

For general specifications of demand, the condition for high-cost firm entry is a sufficient condition for a loss of market share for low-cost incumbents in the hazardous product industry. Hence, whenever increased liability exposure induces the entry of high-cost competitive firms in a dominant firm(s)/competitive fringe model, the market share of each high-cost firm increases and the market share of each low-cost firm decreases.

EXAMPLE 3: Consider the case of Cournot-Nash competition among incumbent firms with the cost functions $c_{i}\left(y_{i}\right)=c_{i} y_{i}+F_{i}, i=l$, h. In this case, both high-and low-cost firms increase production when the marginal benefit schedule becomes sufficiently more elastic following a change in legal structure and, otherwise, decrease output.

For general functional forms of the marginal benefit schedule, total output in the industry decreases whenever $\epsilon>-2 / s_{h}$ and liability is shifted by more than $100 \%$ into price whenever $\Phi<0$. Consequently, liability is shifted by more than $100 \%$ into price whenever 
$\epsilon_{\theta}>0$ for the case of linear marginal benefit, and $1+\eta+\epsilon_{\theta}>0$ for the case of isoelastic marginal benefit.

Critical values for the change in the unit liability elasticity are presented in Table 1 for the case of a linear marginal benefit schedule. As in the case of a dominant firm(s)/competitive fringe market structure, high-cost entry can only occur when the change in the liability elasticity sufficiently exceeds unitary value. As before, a necessary condition for high-cost firm entry is a loss of market share for large low-cost incumbents.

As these examples illustrate, the structural implications of an increase in producer liability are highly sensitive to changes in the unit liability elasticity. In a wide range of circumstances, increased producer liability for environmental health risks induces the entry of high-cost firms in the hazardous sector. Large values of the liability elasticity are associated with the entry of high-cost firms and a loss of low-cost incumbent market share in noncompetitive environments, while the market share of high-cost incumbents may or may not decrease when the entry of high-cost firms occurs.

When producer liability arises from environmental health risk, it is likely that the unit liability function increases with the level of industry output. For example, there is considerable evidence that the health risk associated with carcinogenic substances generally increases with the level of exposure (Lichtenberg \& Zilberman, 1989). Similarly, for firms that pollute a common region, the negative externality associated with production may increase at an increasing rate when the natural sink for environmental contamination is limited.

\section{Conclusion}

This article has considered the impact of product liability on market equilibrium in a wide variety of industry settings. Our main result is that the entry of high-cost firms is more likely to occur when the marginal benefit schedule is convex and when the change in the unit liability elasticity is large. A large, positive change in the liability elasticity implies that the marginal benefit schedule becomes more price elastic at the equilibrium point, which leads to greater shifting of liability into price. In cases where liability is shifted by more than $100 \%$ into price, entry can occur as the marginal profitability of production increases. We also demonstrate that a contraction of total industry output is a necessary condition for small-firm entry to occur following an increase in liability.

In an important article, Ringleb \& Wiggins (1990) found that an increase in producer exposure to liability frequently precedes the entry of small, high-cost firms and leads to increases in the market share of high-cost firms in hazardous sectors of the economy. Ringleb \& Wiggins (1990) hypothesize that such entry results from the desire of large, incumbent firms to shield themselves from liability by divesting risky activities. Our article has demonstrated that incomplete capitalization and divestiture incentives are not the only possible motivations for the entry of high-cost firms to occur in response to increased product liability.

The article clarifies the role of the unit liability function in determining entry incentives in industries with environmentally hazardous output. In a wide variety of circumstances, the entry incentive is fundamentally related to the change in the slope of the unit liability function. In particular, increased producer exposure to liability is likely to result in small-firm 
entry when the slope of the unit liability function increases with the change in liability structure. Under such conditions, increased liability shifts the marginal benefit schedule downward for each incumbent firm but also makes it more price elastic. The imposition of producer liability, thus, may increase industry price-cost margins and lead to the entry of high-cost firms, results that suggest the relationship between liability and market structure is richer than previously recognized.

\section{Acknowledgments}

We acknowledge helpful conversations with Joseph Stiglitz, Jeffrey Perloff, and David Zilberman.

\section{Appendix}

\section{Proof of Proposition 1}

A change in producer liability affects the number of high-cost firms as in Eq. (10). Decomposing Eq. (10) yields, after some manipulation

$$
\frac{d n_{h}}{d \theta}=\frac{-g_{\theta}\left[Y\left(k_{l}\left(k_{h}-\delta_{h} B^{\prime}\right)-B^{\prime \prime} \Psi\right)+\epsilon_{\theta} B^{\prime}\left(\Psi-\delta_{h}^{2} y_{h} k_{l}\right)\right.}{B^{\prime} Y y_{h} k_{l} \pi_{y_{h} y_{h}}^{h}} .
$$

The denominator of Eq. (16) is positive by Eq. (C3), Eq. (C4), and the second-order condition of a high-cost firm in Eq. (3). For an increase in producer liability, the entry of high-cost firms occurs in Eq. (16) whenever $Y\left(k_{l}\left(k_{h}-\delta_{h} B^{\prime}\right)-B^{\prime \prime} \Psi\right)<-\epsilon_{\theta} B^{\prime}(\Psi-$ $\left.\delta_{h}^{2} y_{h} k_{l}\right)$. Dividing both sides by $-B^{\prime}\left(\Psi-\delta_{h}^{2} y_{h} k_{l}\right)>0$ completes the proof.

\section{Proof of Proposition 2}

It is necessary to show that the condition for a (weak) expansion of total industry output contradicts the condition for high-cost firm entry for the case of increased producer liability $\left(\mathrm{g}_{\theta} \geq 0\right)$. Manipulating Eq. (12), total industry output (at least weakly) expands in response to increased producer liability whenever

$$
\epsilon_{\theta} \leq \frac{k_{h}-\delta_{h} B^{\prime}}{B^{\prime} \delta_{h}^{2} s_{h}} .
$$

Comparing Eq. (17) with the condition for high-cost entry in Proposition 1, entry occurs under conditions of total industry output expansion if and only if

$$
\frac{k_{h}-\delta_{h} B^{\prime}}{B^{\prime} \delta_{h}^{2} s_{h}}>\frac{-Y\left[k_{l}\left(k_{h}-\delta_{h} B^{\prime}\right)-B^{\prime \prime} \Psi\right]}{B^{\prime}\left[\Psi-\delta_{h}^{2} y_{h} k_{l}\right]} .
$$


Factoring Eq. (18) yields the condition $\left(k_{h}-\delta_{h} B^{\prime}-\delta_{h}^{2} y_{h} B^{\prime \prime}\right) \Psi>0$. Recognizing the term in brackets to be the second-order condition of a high-cost firm results in a contradiction.

\section{Proof of Proposition 3}

In Eq. (14), the market share of a high-cost firm increases following increased product liability if and only if $k_{h}-\delta_{h} B^{\prime}+\delta_{h} B^{\prime \prime} Y>-\delta_{h} B^{\prime}\left(1-\delta_{h} s_{h}\right) \epsilon_{\theta}$. Factoring this expression completes Part 1. In Eq. (15), the market share of a low-cost firm increases in response to increased producer liability if and only if $y_{l} k_{l}\left(k_{h}-\delta_{h} B^{\prime}\right)-B^{\prime \prime} Y\left(\delta_{l} y_{l} k_{h}+\right.$ $\left.\delta_{h}\left(c_{y_{h}}^{h}-c_{y_{l}}^{l}\right)\right)>-\epsilon_{\theta} B^{\prime}\left(y_{l}\left(\delta_{l} k_{k}-\delta_{h}^{2} s_{h} k_{l}\right)+\delta_{h}\left(c_{y_{h}}^{h}-c_{y_{l}}^{l}\right)\right.$. Recognizing that the term in the brackets on the right-hand side of this expression is positive when $\delta_{l} \geq \delta_{h}$, and factoring completes the proof.

\section{References}

Besley, T. (1989). Commodity taxation and imperfect competition: a note on the effects of entry. J Public Econ 40, 359-367.

Boyd, J., \& Ingberman, D. (1994). Extending liability: should the sins of the producer be visited upon others? Resources for the future discussion paper, 95-05.

Dierickx, I., Matutes, C., \& Neven, D. (1988). Indirect taxation and Cournot equilibrium. Int J Industrial Org 6, 385-399.

Dixit, A. (1986). Comparative statics for oligopoly. Int Econ Rev 27, 107-122.

Hamilton, S. (1999). Demand shifts and market structure in free-entry oligopoly equilibria. Int J Industrial Org 17, 259-275.

Kimmel, S. (1992). Effects of cost changes on oligopolists' profits. J Industrial Econ 40, 441-449.

Konishi, H. (1990). Final and intermediate goods taxation in an oligopolistic economy with free entry. $J$ Public Econ 42, 371-386.

Lichtenberg, E., \& Zilberman, D. The economics of public health regulations. Q J Econ 103, 167-178.

Mankiw, N., \& Whinston, M. Free entry and social inefficiency. Rand J Econ 17, 48-58.

Novshek, W. (1985). On the existence of Cournot equilibrium. Rev Econ Studies 52, 85-98.

Pashigian, P. (1984). The effect of environmental regulation on optimal plant size and factor shares. J Law Econ $27,1-28$.

Ringleb, A., \& Wiggins, S. (1990). Liability and large-scale, long-term hazards. J Polit Economy 98, 574-595.

Seade, J. (1980). On the effects of entry. Econometrica 48, 479-489.

Seade, J. (1980). The stability of Cournot revisited. J Econ Theory 23, 15-27.

Sunding, D., \& Zilberman, D. (1988). Allocating product liability in a multimarket setting. Int Rev Law Econ 18, $1-11$.

van 't Veld, K. (1997). The Judgment-Proof Opportunity. Ph.D. Dissertation, Department of Agricultural and Resource Economics, University of California Berkeley.

Vickers, J. (1989). The nature of costs and the number of firms at Cournot equilibrium. Int J Industrial Org 7 , 503-509.

Watts, A. (1998). Insolvency and division of cleanup costs. Int Rev Law Econ 18, 61-76.

Williamson, O. (1991). Comparative economic organization: the analysis of discrete structural alternatives. Admin Sci Q 36, 269-296. 